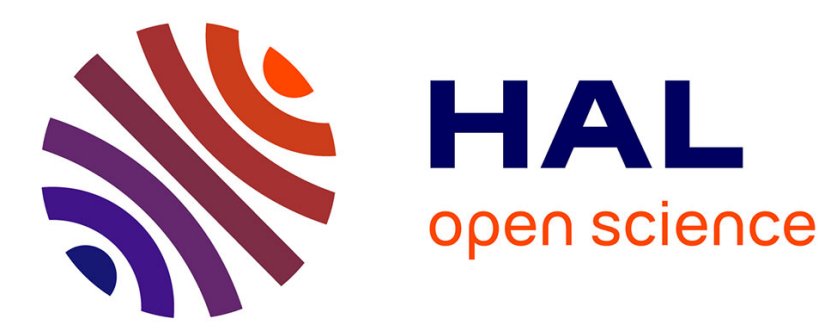

\title{
Belt charging system
}

\author{
M. Letournel, J.-C. Oberlin
}

\section{To cite this version:}

M. Letournel, J.-C. Oberlin. Belt charging system. Revue de Physique Appliquée, 1977, 12 (10), pp.1383-1389. 10.1051/rphysap:0197700120100138300 . jpa-00244328

\section{HAL Id: jpa-00244328 https://hal.science/jpa-00244328}

Submitted on 1 Jan 1977

HAL is a multi-disciplinary open access archive for the deposit and dissemination of scientific research documents, whether they are published or not. The documents may come from teaching and research institutions in France or abroad, or from public or private research centers.
L'archive ouverte pluridisciplinaire HAL, est destinée au dépôt et à la diffusion de documents scientifiques de niveau recherche, publiés ou non, émanant des établissements d'enseignement et de recherche français ou étrangers, des laboratoires publics ou privés. 


\title{
BELT CHARGING SYSTEM
}

\author{
M. LETOURNEL and J.-C. OBERLIN \\ Centre de Recherches Nucléaires, Université Louis Pasteur, 67037 Strasbourg Cedex, France
}

\begin{abstract}
Résumé. - Les courroies des accélérateurs M.P. ont rencontré de sérieuses difficultés principalement au sujet de la durée de vie. Différents paramètres du système de charge par courroie sont analysés et certains d'entre eux sont soulignés comme concourant à la détérioration de la courroie ou à la modulation de tension. Dans cet ordre d'idées, certaines expériences sont actuellement en cours et seront poursuivies afin de pallier à ces limitations de courroie et de déterminer également les possibilités.
\end{abstract}

Abstract. - In M.P. accelerators belts have encountered some difficulties mainly about the belt life time. In the belt charging system, parameters are investigated and some of them are pointed out as being partly responsible either for belt deterioration or for belt ripple. Experiments are and will be carried out to surround the actual belt limitations.

In many places after carrying a lot of nuclear physic experiments, belts seem to have encountered big difficulties, specially in M.P. machines. Belt charging system seems very simple. Corona needles or now screens, deposit charges at the base of the machine and carry them up to the terminal electrode where they are picked up by a screen. In order to double the possibility of charging, negative charges can be drawn from the terminal electrode down to the base. All this has worked well for many years. Besides of some well known advantages as simplicity, a lot of current, transported belt show another characteristic, the voltage ripple, well analyzed by many people $[1$, 2]. This ripple is the modulation in terminal voltage due to the balance between the incoming charge and the outgoing charge tempered through the RC of the terminal electrode. A corona stabilizer have to cope with the free running ripple in order to bring it around 1 or $2 \mathrm{kV}$ [3].

Everyone knows the main characteristics of the belt, but is also aware of some disasters with M.P. belt (Fig. 1). Belt life time is commonly more than 10000 hours in many Van de Graaff machines, but specially in the M.P. machine it has turned out that belt life time is the major critical point, belt duration being generally everywhere of the order of a few thousand hours or even 1 or 2000 hours. Black and $\tan$ belts have shown the same characteristic deterioration process. A ruined belt shows everywhere similar failures: long holes along long stripes either completely punctured through the belt or partially punctured to the belt carcass and on both sides, individual pinholes through the belt, among or besides large mat belt surface areas. A special paper is devoted to this kind of deterioration and structure [4]. The purpose of this paper is to try to investigate some

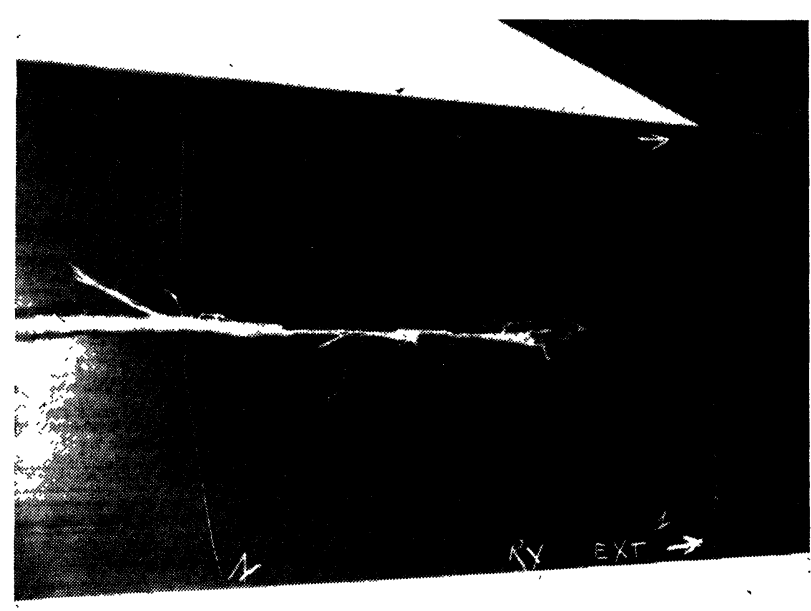

FIG. 1. - Belt breakdown.

fondamental processes in belt charging system, some problems, or some new aspects.

1. Belt - Surface and bulk contact electrification Ripple. - The belt is made of a cotton carcass between two layers of rubber. This rubber has to carry charges and in static electricity there are three electrification processes :

1 - Contact electrification (including tribo and field induced electrification);

2 - Corona charging;

3 - Polarization in electric fields.

There is a strong evidence that contact electrification plays a role in the contact between belt and other material as pulley and guides. In fact, it is probably an important component of the belt voltage ripple. The rubber coating of the belt is a polymer which is able to be strongly charged through 
contact to a metal. On figure 2 we see the experiment of Volta [5] showing transfer of charge after contact between one plate of $\mathrm{Zi}$ and one of $\mathrm{Cu}$. The contact charging metal insulator and specially metal polymer is highly effective and has been studied recently by many people.
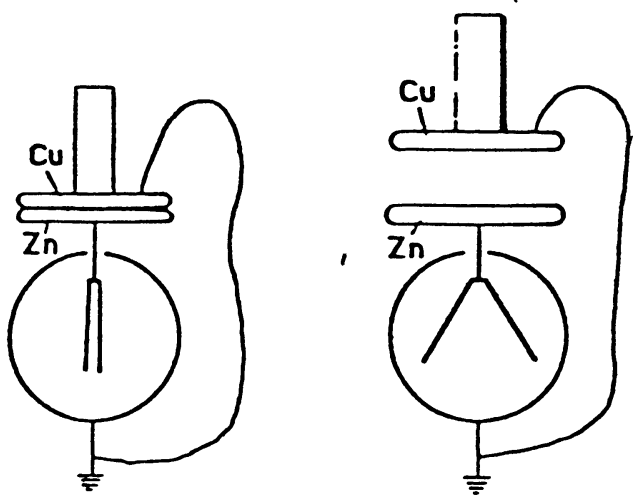

FIG. 2. - Volta's experiment.

On figure 3 Robins [6] shows charges acquired by polymers after repeated contact with a chromium sphere. We can see a kind of saturation with the charge densities according to the number of contacts.
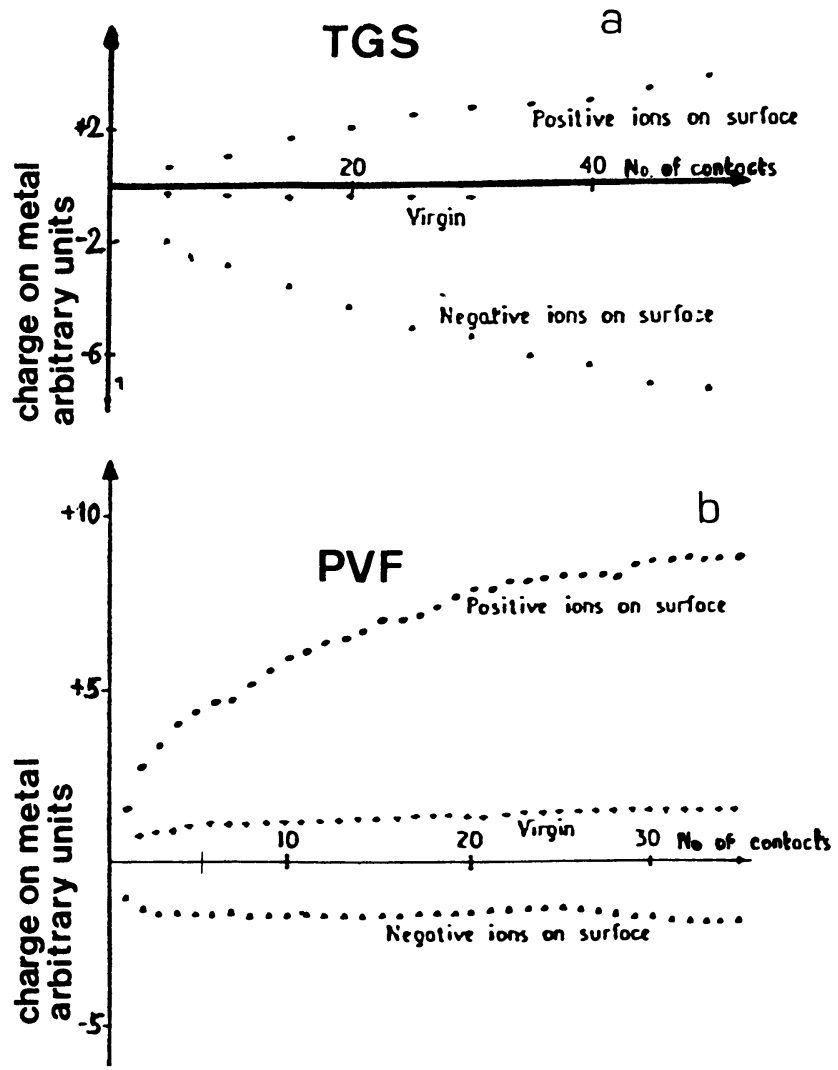

FIG. 3. - Examples of charges acquired after repeated contact.

Contact charging is accomplished mainly by the transfer of electrons and ions. Depending on the nature of the material in contact, the surface condition and external factors such as an electric field traversing the interface a charge transfer will occur. If the materials become separated some, none or all of the charge may remain on the respective surfaces.

This charge transfer has been explained by Davies [7] and Bauser [8] and found to be proportionnal to the difference in the electron work functions of the contacting materials (Fig. 4). And the solid state

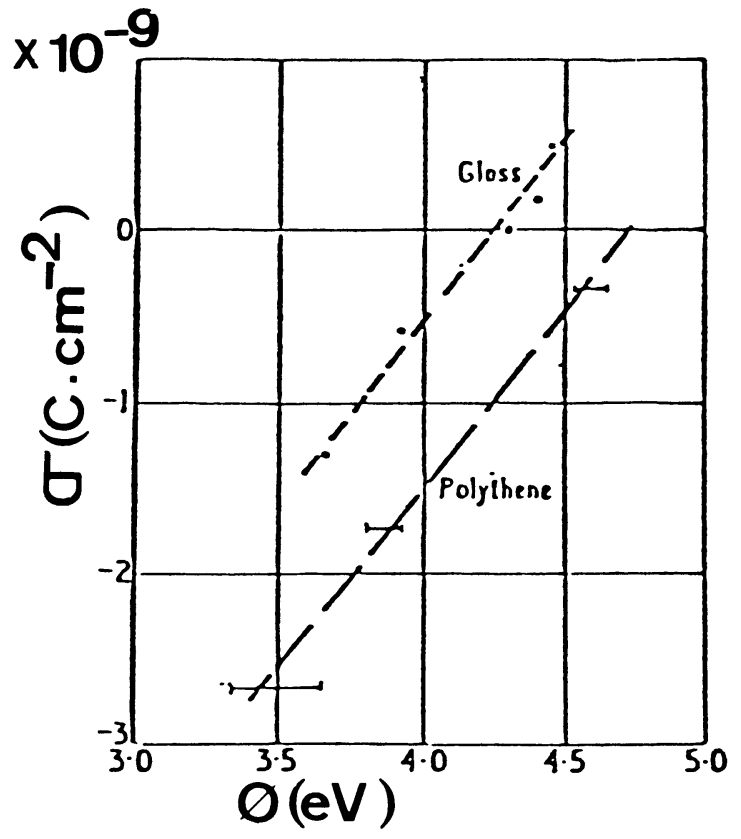

FIG. 4. - Example of charge density against work function.

Physics approach has given an explanation similar to that for inorganic semiconductors. In static electrification of solid insulators by metal contacts, electrons are transferred from a metal to an insulator or reverse depending on the distribution of the energy levels involved. Figure 5 shows the energy band [9]

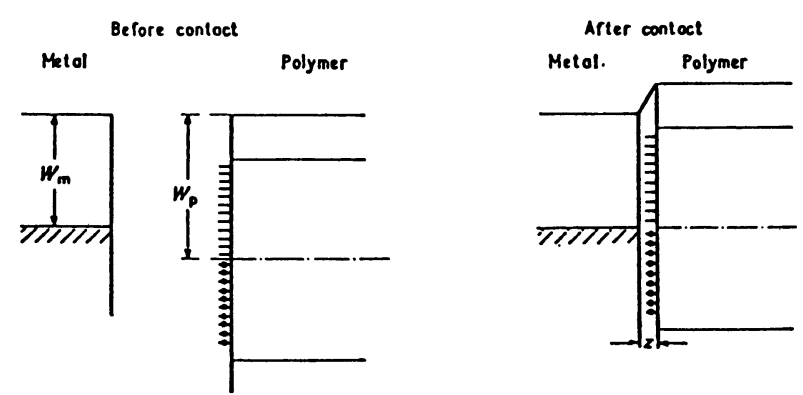

FIG. 5. - Contact between metal and polymer a) before contact b) after contact.

schema for a metal and an insulator before and during contact. The charge [10] densities produced by contact depend on the nature and also on the pressure of the contacting materials. Cleves has shown the strong dependance [10] of the charge density with the humidity. And it seems very useful to think about a fan or a drying device inside the tank to accelerate the removal of moisture, just after closing the tank. In an M.P. $400 \mu \mathrm{A}$ on a belt means a density of $4 \mathrm{nC} / \mathrm{cm}^{2}$, 
and the charge transfer is very significant. Charge densities of $10^{-9} \mathrm{C} / \mathrm{cm}^{2}$ or more can be generated when a metal is brought into contact with an insulator sample. The electron transfer is instantaneous but it depends how the contact area is defined and in practice build up of charge is made after several contacts depending on how the contact is made and also depending on the nature and the cleanliness of the surface, and the contact pressure [10]. Mordhage has shown the dependance of the charge density in contact with an applied electric field [11]. Polymers absorb water which may modify the electronic structure of the polymer and determine a strong dependance on the charge transfer. An experiment that we have carried out with Coste and Pechery on a Van de Graaff belt sample in $30 \%$ relative humidity has shown negative charge transfer of the order of $2 \mathrm{nC} / \mathrm{cm}^{2}$ at each contact, 10 contacts giving $15 \times 10^{-9} \mathrm{C} / \mathrm{cm}^{2}$. These experiences are very well reproducible but values are different from a sample to another or even from one place to another on the same belt sample . Humidity plays a major role.

It is long known that rubbing insulating material one on the other or on metal, make them to get charge of a certain. sign. Triboelectric lists or series of different materials are in many books [8], and belt do not avoid such a phenomena, which is very complicated. Slipping belts, high or low ripple depending on belt tension, might imply a component coming from this negative charge transfer onto the belt.

From the mechanical point of view of a pure contact and separation avoiding any sliding, the charge density is proportional to the difference in work function of the contacting partners. As soon as gliding or friction occurs, the phenomenon is far more complex and less reproducible. And what is contact and what is friction? Studies of the electrostatic charges developed by friction under well controlled conditions specially for relative humidity have been done by Coste and Pechery $\left({ }^{1}\right)$ with an aparatus where there is a belt rotating on rollers and gliding is assured by one of the rollers which can turn as the same speed or speed up or down or stopped. A certain pressure can be applied. The remarkable results of thousands of experiments of different materials is that it is possible to divide the results in three different types (Fig. 6).

I - Charge density is growing up to a constant

II - Charge density goes through a maximum, then decreases, changes polarity to obtain a new equilibrium state.

III - Charge density goes through a maximum, decreases to a constant level without polarity change.

(1) COSTE J. and PECHERY P. Private communication.
Experiences are now being carried out with a belt and it seems that belt is of the type I. It seems that when we stop the friction, the normal polarity and charge transfer occur in the same way as before but it

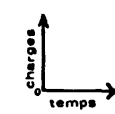

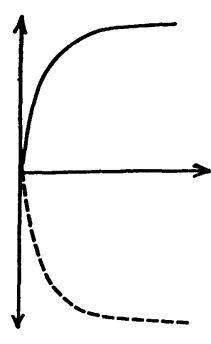

cas 1

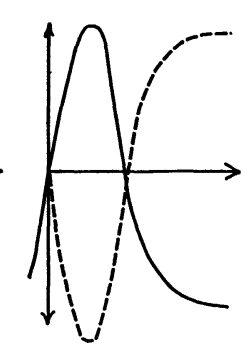

cas 2

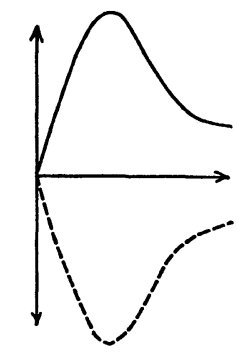

cas 3
FIG. 6. - Charging friction effect versus time.

is not always the case and results are dependant of the surface itself and many factors.

For a belt, for example a M.P. belt, belt is driven by a drive motor whose drum is a designes, with 17 grooves separated of 1 inch in order to let the gas escape. This pulley is slightly crowned from the two last grooves on each side, down to the end. On the alternator pulley crowning is also made on 2 inches on each side. There the slippage effect is obvious and is in the order of some $\mathrm{cm} / \mathrm{s}$., on the belt wings. The mechanical load of the belt is high and obviously not the same along the belt width because of the grooves, and also in time, according to all the mechanical vibration modes of a running belt. All these factors in addition to the electric up charge field are part of the parasitic charge transfer, and probably of the ripple.

Some loading on the normally non grooved alternator determines also the slippage of the alternator compared to the belt. This phenomenon leads to induce a certain amount of negative charges deposited onto the terminal internal belt face. Due to the modulated load slippage, it determines an erratic voltage ripple sometimes higher in SF6 than $30 \mathrm{kV}$ and hard to stabilize. The functionning of the solution brought through the French connection (12] (Fig. 7) was not clear in the beginning, but can be now explained by induction of an equal amount of charge of opposite polarity induced through the second post alternator screen onto the external belt side to compensate the internal parasitic charges.

2. Corona charging process. - About the corona charging it is known that from a sharp needle or a very thin wire, the electric field around those sharp points may increase beyond the breakdown strength and corona discharges appear. The gas around the wire or needle is highly ionized and ions of one nature 


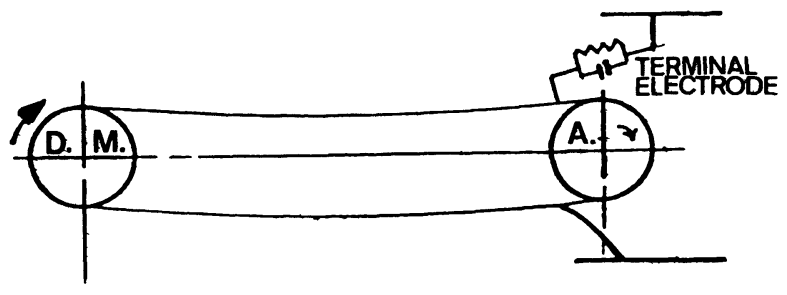

FIG. 7. - French connection device.

positive or negative go along the electric lines of force and depending on the field in the gap and the ratio of point radius to gap length, the streamers start with very high speed and slow down to velocity of some $100 \mathrm{~m} / \mathrm{s}$ or more. Two things must be pointed out, first for the layer of charges on the insulator, the extreme sensitivity to the excess potential on the cathode, second the strong dependance of the current on the geometrical characteristics of the wire or needle. In other words, it would be not surprising for a row of needles or a screen to have the current coming not from each point but mainly from some of them.

3. Double transportation possibility. - If we introduce an insulator into an electric field determined by a constant voltage $U$. After a certain time, due to deposit of ions of same sign, the final state of this insulator is as shown on the figure $8 \mathrm{a}$ where the field
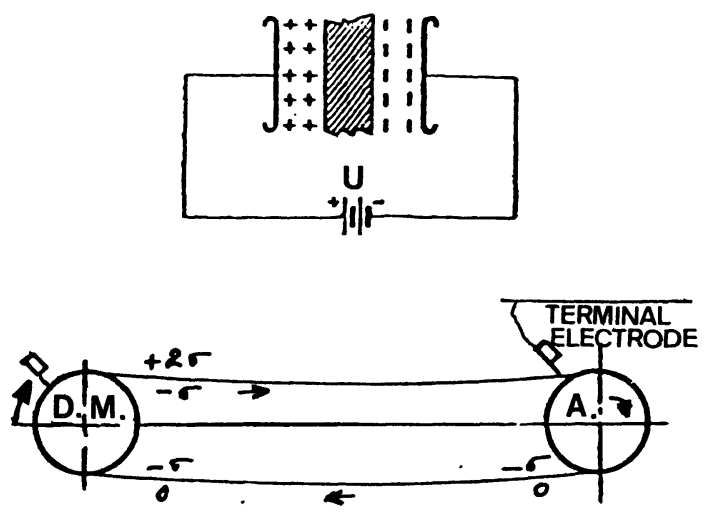

FIG. 8. - a) Insulator between two plates.

b) Natural double transportation.

between the insulator surfaces and the electrode is first reduced, then reduced to zero. In 1953, Gartner [13] showed that the electrostatic machines could run under certain conditions along the double natural charge transportation. Figure $8 \mathrm{~b}$ shows this principle. For a certain field, and mainly if we get ionization under the inductor plate, there is deposit of negative charge density $-\sigma$, charge bound after a certain time in the belt and never removed. The charging system works then that way only in a case of upcharge. A charge density $2 \sigma$ is put on the belt by corona discharge for example outside the belt and removed by a screen or needle in the terminal electrode. The charge ${ }^{-} \sigma$ is built up after some turns on the internal belt side. This way of charging allows to carry a double density. Only the insulator, belt material encounters an extra strain. This double natural charge transportation is a possibility at least partially in the Van de Graaff machines. Experiences of internal belt charging have proved that charges stay without being substantially removed by the terminal pulley, and all the conditions are there to allow partly that kind of charging. This process can lead to a non uniform pattern of charges bound on the internal belt side due mainly to the parasitic charges and the non uniform drive motor geometry. It can influence strongly the non uniform deposit of charges by corona process. To avoid this possibility, try of belt charge removal can be done simultaneously on both sides after the terminal pulley (Fig. 9).

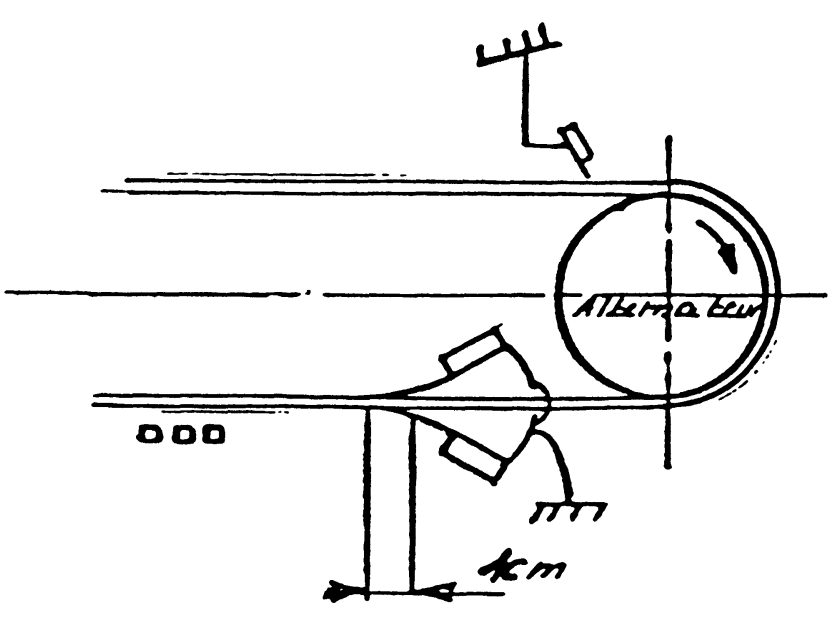

FIG. 9. - Double discharge screen.

4. Charge removal. - Removal of charges from a charge insulator can be done through different processes but mainly through the field produced by the charged belt itself near the top of grounded points or wires which ionized the gas. Negative ions are then projected on to the charged belt in such a way us to neutralize the excess field at each instant. In the case of the (Fig. 10), these ions are deposited on a well
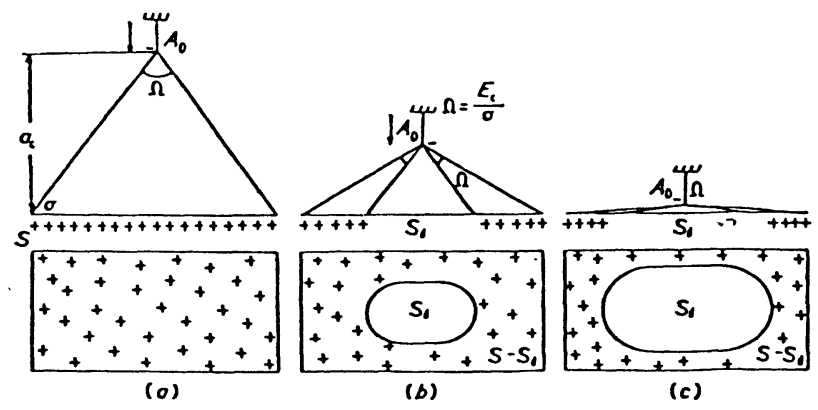

FIG. 10. - Discharge mecanism of a foil due to an approaching earthed point:

a) before the projection of ions,

b) during the projection of ions,

c) after the projections of ions. 
defined surface, the dimensions of which depend on the charge density and on the proximity of any conductors [14].

Whatever the speed is, a grounded screen or serie of needles will usually discharge the belt to an average charge density of about $100 \mathrm{pC} / \mathrm{cm}^{2}$ that means for the belt charge current, in the order of $1 \mu \mathrm{A}$ or less. If there is enough space free of conductors, this eliminator works properly but there are other means to reduce this value if necessary. As the initial speed of these ions is greater than $10^{5} \mathrm{~cm} / \mathrm{s}$ the discharge follows the field variations almost instantaneously. And in case of a H.V.E.C. belt arrangement and in order to prevent influence from one side on the other, two screens with longwires one on each side, facing each other on one $\mathrm{cm}$ distance can be added after the terminal pulley, with good result to take care of both sides (Fig. 9). To measure the efficiency of a charge eliminator Lövstrand [15] made a machine which indicated the better residual charge density results with $25 \mu$ wires and the dependance with the band velocity, the charge density and the nature of the eliminators.

Under the usual Van de Graaff machine conditions, as the charged belt voltage can not be higher than this determined by the belt capacity itself, with charge density higher than $4 \mathrm{nC} / \mathrm{cm}^{2}$, two neutralizing steps can be considered in order to prevent a spontaneous discharge, before the proper removal. The first step must be in a metallic environment which keeps the belt charge capacity high enough. It means that the first screen must be at a distance not greater than some 2 to $4 \mathrm{~cm}$ from the ground, or in another hand belt must be protected by a grounded plate not too far from the first screen.

5. Physical processes involved with belts. - A belt has to be treated as an insulator of a resistivity of the order of $10^{12} \Omega \mathrm{cm}$. Then with no free electrons on the rubber surface, the cotton carcass of resistivity of the order of $10^{9} \Omega \mathrm{cm}$ being there from the electric point of view to allow a good distribution of the potential. Consequently charging process, removal process and charge transportation must be explained with this particular view of an insulator. First, speaking about the so called rearranging of charges on the belt to explain ripple or loss of charges in normal running conditions, it is impossible. As Zichy point out [16], charges are firmly bound inside the belt polymer structure and it is impossible for them to move except through gas ionization determined in a fixed field configuration by the belt holding capability. Second, the exchange of belt charges or the neutralizing of these charges proceeds, under normal conditions only through the incoming of ions of opposite polarity created in the gas. Electric lines of force (Fig. 11) coming from the top surface of a charged belt are strongly influenced by the ground and directed towards the nearby conductors. The field configura-

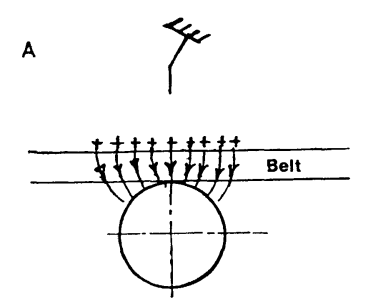

no charge removal

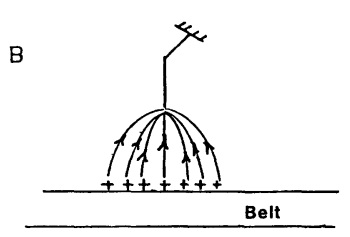

charge removal

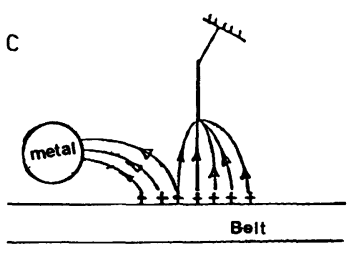

field configuration

D

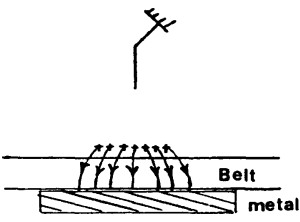

no charge removal
E

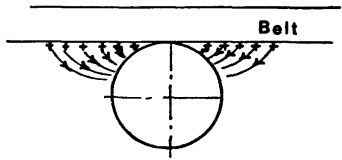

no charge removal

Fig. 11. - Electric lines of forces configuration.

A. Charged belt on pulley with a screen.

B. Charged belt alone with a screen.

C. Charged belt, screen and nearby conductor.

D. Charged belt on plate, screen.

E. Internal charged belt.

tion in the pressurized gas depends on the geometrical position of the nearby conductors and other neutral or charged objects (C). Then, to act properly, charge removal determined by the belt charge field itself must be accomplished far enough from conductors (B), otherwise the field created on the screen is to low to allow a complete neutralization (D). On the contrary this phenomenon also explains why it is impossible to remove any charge at all even with a grounded screen from the external side of a charged belt right onto a metallic pulley (A). By lack of field, we must create an additional electric field in order to neutralize the charge or eventually to charge with the other polarity, by incoming ions of opposite polarity which is the case of down charging. The field must be strong enough only where charging or charge removal has to occur. This explains why under normal conditions, charges can stay during an infinite time without being removed and are the basis of the terminal voltage repetitive ripple and of the possible double natural transportation. Particularly charges bound in the belt inside surface are not removed by contact on metallic pulleys (E). But, in another hand, we can think also about the use of this particularity to imprint durable charges onto a proper belt location just to balance the repetitive voltage ripple. 
6. Charge transportation. - Another fundamental problem is the charge transportation through the total structure. It is governed essentially by the concept of charge belt capacity, the deduced potential, and gas rigidity.

The main aspect of the charge transportation is studied elsewhere [4], and gives an explanation for the M.P. belt deterioration. About the other possible belt failures $\left({ }^{2}\right)$, voltages tracks, surface or volume breakdowns are mainly due to a malfunctioning or improper operation somewhere. Over voltage or over charging of the belt, poor charge spray or collection, inducting inhomogeneity, wet gas or lack of conditionning are the probable causes of failures. The importance of belt moisture removal before normal operation has to be emphasized. If charges move on a belt surface, it is because of too high a tangential field and a reduced surface resistivity due for example to moisture.

7. Modifications in structure. - In May 1976, chasing the kind of trouble due to M.P. belt deterioration which was patent at this time through a current leakage on the internal structure section 8 and following the Van de Graaff and Trump concept of controlling voltage on the belt, we took all spacers and control rods away. From the drive motor to the terminal pulley, the belt was not allowed to touch anything except the four screens. So the outside guides and bars were positioned to follow as best we could the practical running curve of the belt which is something as a catenary curve. Spacers and gradient rods were roughly at a distance of 1 inch from the up run and $1 / 2$ inch from the down run which was not charged. The mechanical ripple was in the order of $1 \mathrm{~cm}$ for the belt wings but not more than $5 \mathrm{~mm}$ for the middle. To control from outside, we added 3 lamps (Fig. 12) in

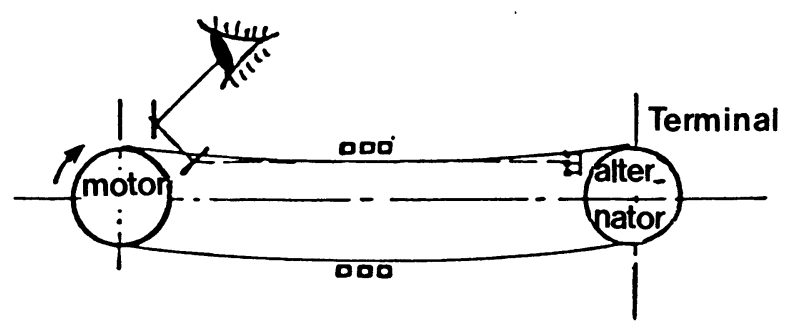

FIG. 12. - Half open structure without rollers.

the terminal in vertical setting which we watched through a mirror system. We ran with this structure with exactly the same voltage characteristics up to $13 \mathrm{MV}$ and with no difference at all from previous behaviour.

This half open structure is fine. Since then in order to stabilize and smooth the machine, we have installed insulated rollers (Fig. 13) in dead sections, termi-

(2) H.V.E.C. Private communication.

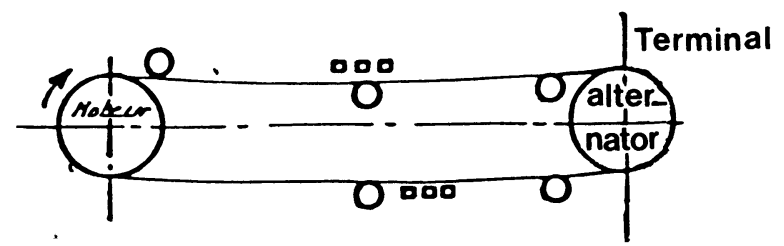

FIG. 13. - Half open structure with some rollers.

nal electrode and high energy position. Some of them are coated with rubber and they all run at floating potential (Fig. 14). We still had the same voltage

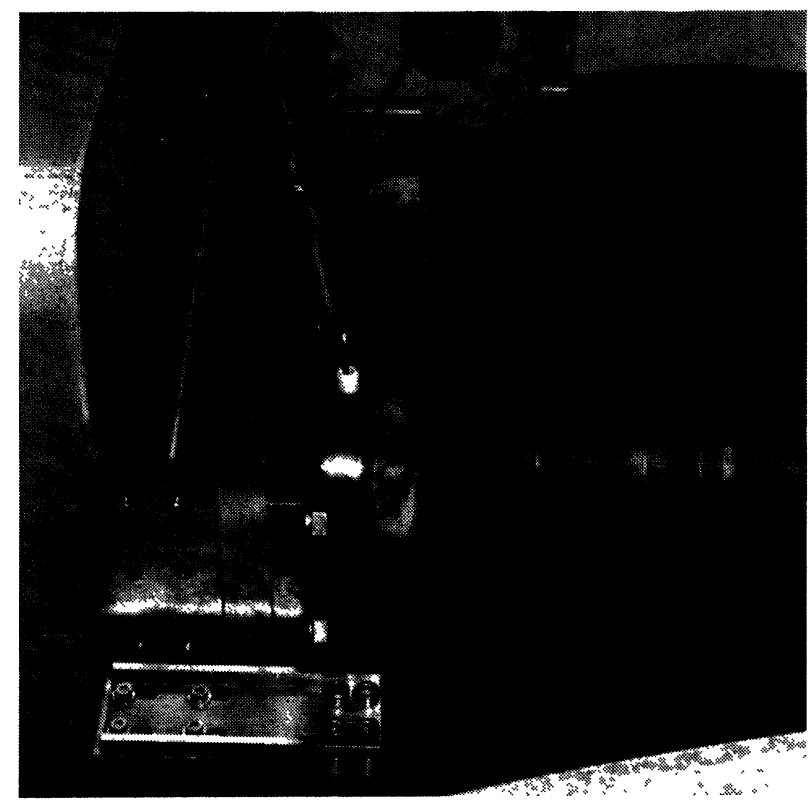

FIG. 14. - Rubber coated roller.

characteristics and the rollers run perfectly well. They will be used in the future to better define and stabilize belt charges.

Figure 15 and figure 16 show the alternator and drive motor covered with two kinds of rubber, and with holes which evacuate the SF6 gas towards the ends. They have been tried successfully in the machine as regards voltage. Besides the good friction coefficient, the reason to have rubber is that the best non electrification transfer contact takes place between two material of the same nature. Antistatic rubber can also be used in order to eliminate parasitic charges. But we can not keep them like that, because of a belt transversal abrasive displacement, on the antistatic black rubber. They correspond to the final design and we have decided to replace this rubber by an identical sleeve of metal, just thicker.

As far as the stability is concerned, the same philosophy as for the pelletron must be considered, to control the total terminal charge bilan. We must try to cope with the total belt charge including the parasitic charges. A good direction is certainly to think as Langsdorf [17] of treating belt charging and discharging by induction. He mounted a belt charging induction device with corona needles on the internal 


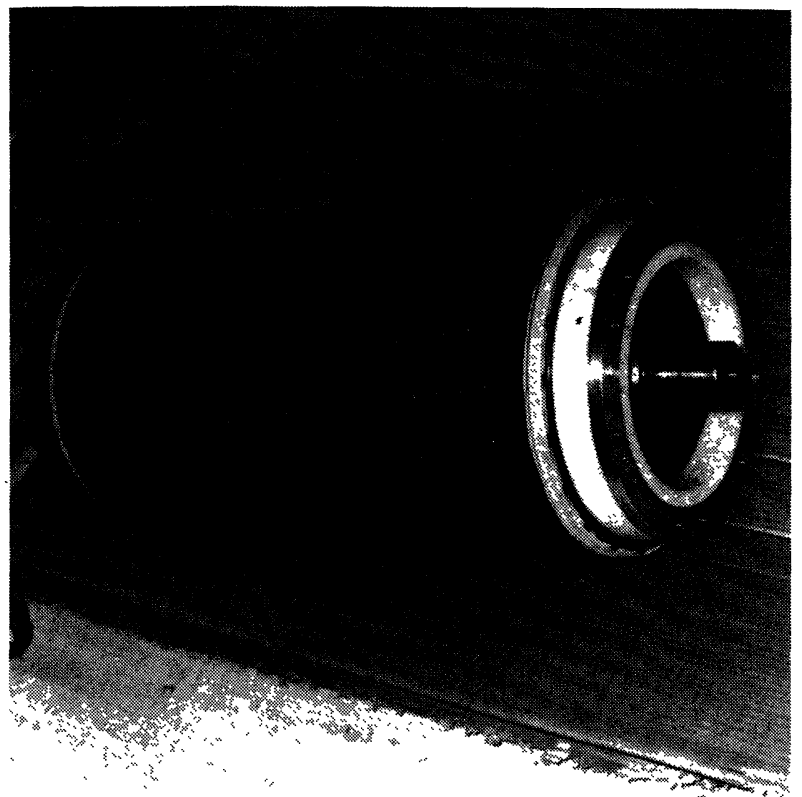

Fig. 15. - Rubber coated alternator.

belt face and brought the terminal free running ripple in the order of 300 or $500 \mathrm{~V}$.'Blythe [18] presented a similar induction device with corona wires. $\mathrm{He}$ succeeded to control charge density for charging and discharging with a very accurated way. His device

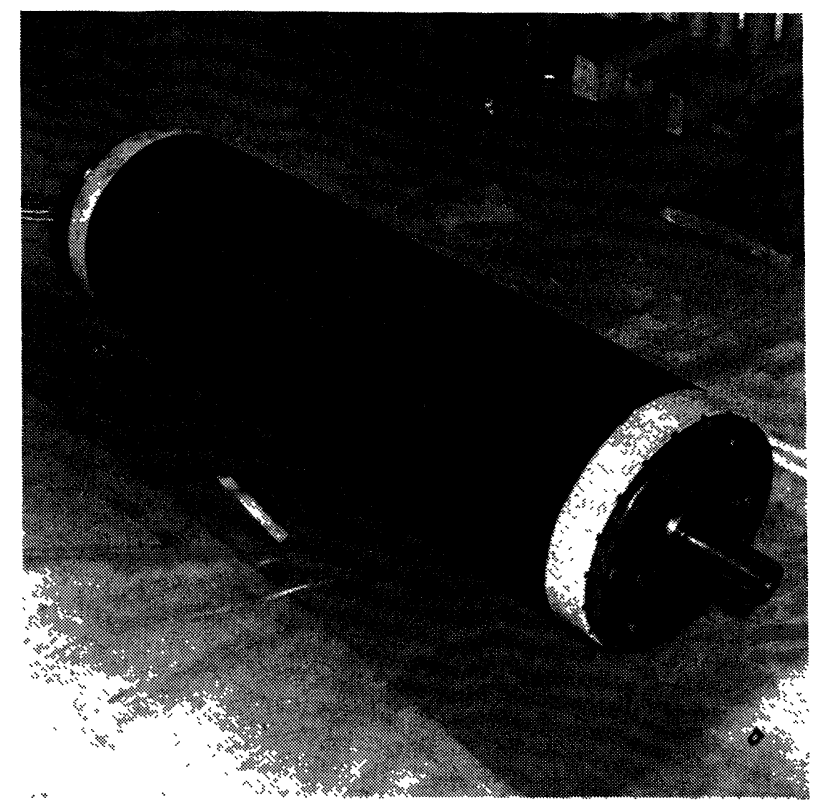

FIG. 16. - Rubber coated drive motor.

does not operated in normal Van de Graaff running conditions, but joined to our rollers, with some changes it can bring a great improvement to control the charge dénsity and therefore the terminal voltage ripple.

\section{References}

[1] Weitkamp W. G. and Schmidt F. H., Nucl. Instrum. Methods 122 (1974) 65

[2] VermeER A. and Strasters B. A., Nucl. Instrum. Methods. 131 (1975) 213.

[3] Thieberger P., Lindgren R., McKeown M. and WeGNER H. E., Nucl. Instrum. Methods 122 (1974) 527.

[4] Letournel M. and Belt M. P., Revue Phys. Appl. 12 (1977).

[5] Ruppel W., (Dechema-Monographien) Nr. 1370-1409, 1973, 321.

[6] Robins, Rose A. C., InNes and Lowell J., Inst. Phys. Conf. Ser 27 (1975) 115.

[7]Davies D. K., Inst. Phys. Conf. Ser. 4 (1967).

[8] BAUSER H. (Dechema-Monographien) Nr. 1370-1409, 1973, 11.

[9] Krupp H. Inst. Phys. Conf. Ser. 4 (1967) 1.
[10] Challende R. F. Advances in Static Electricity Vienne AuxiliaBrussels 1970.

[10*] Cleves A. C., Inst. Phys. Conf. Ser. 11 (1971) 226.

[11] Nordhage F. and BäCKström G. Inst. Phys. Conf. Ser. 27 (1975) 84.

[12] Tandem accelerator Conference 1974 Rehovot - Israël.

[13] Gartner E., R.G.E. Février et mars 1953 t. 62 71-86, 136-154.

[14] Bertein H. Inst. Phys. Conf. Ser. 4 (1967) 11.

[15] Lovstrand K. G. Inst. Phys. Conf. Ser. 27 (1975) 246.

[16] Zıсну E. L. (Dechema-Monographien) Nr. 1370-1409, 1973, 147.

[17] Langsdorf A. Proc. Int. Conf. on the Techn. Elect. Acc. Daresbury (1973) 255.

[18] Blythe A. R. Inst. Phys. Conf. Ser. 11 (1971) 226. 